\title{
Environmental evaluation of pareto optimal renovation strategies: a multidimensional life-cycle analysis
}

\author{
Yanaika Decorte ${ }^{1, *}$, Marijke Steeman ${ }^{1}$, Nathan Van Den Bossche ${ }^{1}$, and Klaas Calle ${ }^{1}$ \\ ${ }^{1}$ Ghent University, Faculty of Engineering and Architecture, Department of Architecture and Urban Planning, Sint Pietersnieuwstraat \\ 41 B4, 9000 Ghent, Belgium
}

\begin{abstract}
The substantial contribution of buildings in the energy consumption and emissions renders the existing building stock a key element to tackle the climate crisis. Consequently, defining a deliberate decision-making process gains importance. Decisions are currently often based on building codes, budget, and in the best case Pareto optimality of the energy performance and the net present value of the life-cycle cost. The growing attention to sustainability, however, raises questions about the effect of environmental considerations on the outcome of the Pareto optimal solutions. This study quantifies the effect of including the environmental aspect as a third dimension to the current evaluation approach. Therefore, the most appropriate renovation measures are selected using a multidimensional Pareto optimization. The method is applied to a residential high-rise building in Belgium. Firstly, the Pareto front is constituted based on lifecycle costing and life-cycle assessment separately. Subsequently, the respective results are combined into an integrated life cycle approach by enumerating the LCA results as an external cost to the LCC results. The results show that the Pareto optimal solutions from a financial and environmental perspective do not coincide. Although the financial aspect dominates, adding the environmental cost eliminates lowperformant financial optima, leading to optimal solutions with a larger insulation thickness.
\end{abstract}

\section{Introduction}

Over $90 \%$ of the European existing building stock was built before 1990 [1]. The substantial contribution of these buildings in the global energy consumption and greenhouse gas emissions renders the existing building stock a key element to tackle the climate crisis and to improve its energy performance.

By 2050, the European greenhouse gas emissions need to be cut by $80-95 \%$ [2]. A vast $97 \%$ of the buildings need to be renovated to meet these 2050 climate targets, whereas the current European renovation rate is only $1 \%$, which is clearly insufficient to reach those goals [3]. Increasing the renovation rate could significantly reduce both the global energy consumption and the environmental impact of the existing building stock [4].

To tackle the urgent need of increased renovation rates, a wide range of renovation strategies is available. However, the uncertainty about which strategy provides the optimal fit for an individual case counterbalances this accessibility. Establishing a deliberate decision-making method considering different renovation measures thus gains prominence $[5,6]$.

Whereas to date determining an optimal renovation solution is simply based on a trade-off between the (code-compliant) energy performance, the construction costs and in a best-case scenario the net present value of the life-cycle cost, barely any other dimension, such as environmental objectives, is considered [5,7]. This approach does not align with the rising focus on sustainability [6].

Hence, this paper examines the impact of both environmental considerations and a life-cycle approach on the initial Pareto optimal renovation set outcome, solely based on the construction costs and the energy performance of a building. A preliminary multidimensional decision-making tool is developed combining life-cycle costing (LCC), life-cycle assessment (LCA) and Pareto optimisation to find the most appropriate renovation strategies for an individual case.

Subsequently, the calculation tool is tested on a residential high-rise building, Kielpark. Since for highrise buildings the façade takes up the largest share of the building envelope components, seven façade renovation strategies are evaluated from a financial and environmental point of view. First, a comparison is made between the results considering initial costs only and life-cycle cost, both on financial and environmental level. Subsequently, the financial and environmental Pareto front is constituted separately to finally enumerate the LCA results as an external cost to the LCC results.

\footnotetext{
* Corresponding author: yanaika.decorte@ $@$ ugent.be
} 


\section{Methodology}

\subsection{Multidimensional decision-making tool}

For this study, two existing methods - life-cycle costing (LCC) and life-cycle assessment (LCA) - are combined into one single decision-making tool, evaluating both the financial and the environmental impact of seven different façade renovation strategies based on Pareto optimisation. This tool is later tested on a case study, explained in $\S 2.2$.

First, an LCC study determines the most feasible façade renovation measures from a financial perspective. Subsequently, to evaluate whether the financially optimal solutions are also viable regarding the environmental impact, an LCA study is in turn performed. The ambition is in the end to get an insight in the relative importance of LCC and LCA, and in the difference between the initial decisions made from a financial point of view and the final outcome based on the enumeration of both results.

\subsubsection{Boundary conditions}

In order to limit disparities, the boundary conditions related to the LCC and LCA study are to the extent possible harmonised. In this way, a comparison of both studies can be made on an equal basis and an enumeration of the individual results is justified.

The boundary conditions refer to several aspects. First of all, the system boundaries, i.e. the process stages included in the life-cycle analysis, of both studies should be at least comparable. Not all aspects are assumed in both studies, since the weight of the different process stages differs from a financial and environmental perspective. For example, the construction and maintenance phase are excluded in the LCA study because of the high uncertainties and the relatively limited impact $[8,9]$. The same applies for the end-of-life phase. On the one hand, there is a large range of possible waste treatment processes of which the impact is still unknown or insecure. On the other hand, the current waste processes are assumed for future processes. These procedures will probably change, rendering the results uncertain and unreliable [9]. An overview of the system boundaries regarding LCC and LCA, respectively, is shown in table 1 .

Table 1. System boundaries included in LCC and LCA.

\begin{tabular}{|c|c|c|c|}
\hline & & LCC & LCA \\
\hline \multirow{4}{*}{ Initial phase } & Demolition & $\times$ & \\
\hline & Materials & $\times$ & $x$ \\
\hline & Transport & $\times$ & $x$ \\
\hline & Construction & $\times$ & \\
\hline \multirow{3}{*}{ Usage phase } & Replacement & $\times$ & $x$ \\
\hline & Maintenance & $\times$ & \\
\hline & Operational energy use & $x$ & $\times$ \\
\hline End of life & Residual value & $\times$ & \\
\hline
\end{tabular}

Besides the system boundaries, the functional unit and total lifespan are equated. Generally, a life span of 10 to 20 years is assumed in LCC studies. This is in contrast to most LCA studies, where a longer lifespan of 60 years is more common. In this work, an average lifespan of 30 years is considered for both LCA and LCC. Based on the results, an estimate of the impact of a shorter or longer period can also be evaluated.

\subsubsection{Life cycle costing (LCC)}

To calculate the life-cycle cost, the commonly used Net Present Value (NPV) method is adopted from a microeconomic point of view including taxes and excluding subsidies to get results independent of future policy changes [6].

The NPV is determined by enumerating the initial costs and all periodic and annual costs during a predefined lifespan discounted to the year of the investment [10].

$$
N P V=I C_{F}+P V\left(E C_{F}\right)+P V\left(M C_{F}\right)-P V\left(R V_{F}\right)
$$

$\mathrm{IC}_{\mathrm{F}} \quad$ Financial initial cost

$\mathrm{EC}_{\mathrm{F}} \quad$ Financial operational energy cost $[€]$

$\mathrm{MC}_{\mathrm{F}} \quad$ Financial maintenance cost $\quad[€]$

$\mathrm{RV}_{\mathrm{F}} \quad$ Financial residual value $\quad[€]$

PV Present value [-]

As shown in (1), no replacement costs will occur as the lifespan of the individual constituting elements is assumed larger or equal to the period considered in this research.

Firstly, the initial financial cost includes demolition, building materials, labour, indirect costs (e.g. equipment, transport,...) and $6 \%$ VAT. The cost data are mainly collected from the ASPEN price dataset regarding new buildings published in 2014 [11]. As these prices evolve rapidly, they are updated to 2019 based on the historical evolution data of the ABEX [12]. An additional 10\% cost is added related to the attention to construction details.

Secondly, to calculate the operational energy cost, data is collected from Eurostat based on the gas prices for household consumers in the first half of 2019. An energy price of $0.0429 € / \mathrm{kWh}$ is applied [13].

Thirdly, the maintenance cost is based on maintenance cost data, collected from the ASPEN price dataset regarding renovations published in 2003 [14], and on the maintenance period. Maintenance costs independent of the renovation strategies such as washing the windows and painting the interior surface are not included.

Fourthly, to calculate the residual value of each façade renovation strategy, the initial cost is multiplied by the ratio of the remaining lifespan and the initial lifespan. The lifespan of S1, S2 and S4 is 30 years, whereas the lifespan of the other strategies is 50 years (see table 3, section 2.2.2). The façade will thus have a remaining lifespan of 0 or 20 years, respectively. 
Finally, in order to convert the future costs to a present value, different economic parameters are defined. Since the discount rate is often considered equal to the interest rate for bank loans, a financial discount rate of $1,8 \%$ is preferred $[15,16]$. Besides that, a growth rate for energy prices of $1,6 \%$ is defined to consider energy price evolutions [17]. Whereas the prices of building materials and labour also fluctuate in time, the corresponding growth rate is further neglected in the analysis.

\subsubsection{Life cycle assessment (LCA)}

The environmental impact assessment is conducted using SimaPro version 9.0.0.49 with the Swiss Ecoinvent database version 3.5 as the life-cycle inventory database containing all required input flows that fit the European context [18].

Furthermore, the MMG assessment framework [19], developed by the Public Waste Agency of Flanders OVAM, is preferred for several reasons to quantify the environmental impact. Firstly, the method is created for and adapted to the Belgian context. In addition, a wide range of impact categories are taken into account consisting of seven standard CEN indicators according to the European standard CEN TC 350 and ten additional $\mathrm{CEN}+$ indicators covering the Belgian policy themes. Finally, other commonly used methods, such as the ReCiPe method [20], define an environmental impact score expressed in points. However, this hampers the comparison with the LCC results expressed in euros, and thus the decision-making process. The MMG method on the contrary, determines an aggregated score by weighing the results through monetary valuation. Each individual environmental impact indicator is linked to a monetarisation factor which indicates an environmental damage cost. The sum of all monetised impact indicators results in the final environmental cost [19].

In contrast to the financial costs, the environmental results are not discounted in this research since no general agreement is yet established in literature on a suitable discount rate [21].

As shown in Table 1, both the embodied and operational energy are included in the LCA study. The construction phase is not included, but 5\% material loss during this phase is considered [19]. A part of the materials is lost due to e.g. storage, cutting losses, careless handing.

\subsubsection{Energy calculations}

To get an insight in the operational energy use, a simplified steady state model is used based on the degree-days method. In this work, only the energy demand for space heating is considered (2). All other types of energy demand (e.g. domestic hot water demand and electricity demand for auxiliary installations and household appliances) is assumed identical for the different renovation strategies and is therefore not simulated. This allows to only evaluate the difference in energy performance due to the façade renovation.
Note that this simplified approach does not compensate for user behaviour and might overestimate the energy use for poorly insulated buildings, and underestimate the energy use of well-insulated buildings.

$$
\mathrm{Q}_{\mathrm{h}}=0.024 \times \mathrm{H} \times \mathrm{HDD} / \eta_{\text {sys }}
$$

$\begin{array}{lll}\mathrm{Q}_{\mathrm{h}} & \text { Annual heating demand } & {[\mathrm{kWh}]} \\ \mathrm{H} & \text { Heat loss coefficient } & {[\mathrm{W} / \mathrm{K}]} \\ \mathrm{HDD} & \text { Heating degree days per year } & {[-]} \\ \eta_{\text {sys }} & \text { Heating system efficiency } & {[-]}\end{array}$

To determine the heating system efficiency, the building is assumed to be heated by a central gas condensing boiler with an average efficiency of 0.90 . An additional loss factor of $30 \%$ is considered related to distribution losses [22].

Furthermore, the number of degree days per heating season is estimated in a simplified way for the next 30 years based on a declining trend of the average number of degree days measured in Belgium per ten years since 1960. These numbers are calculated using $16.5^{\circ} \mathrm{C}$ as the indoor and outdoor temperature above which heating is no longer required. The assumed degree days per year are 2155, 2066, 1977 and 1888 in 2020, from 2021 to 2030, from 2031 to 2040 and from 2041 to 2050 , respectively [22].

\subsubsection{Pareto optimisation}

In this research, three criteria - LCC, LCA and the operational energy use are evaluated. As pareto optimisation is often used to simultaneously optimise multiple criteria, this concept is most appropriate in this study [9].

Moreover, a multi-objective optimisation approach is followed. The optimisation objectives are a minimal operational energy use, initial financial cost, life-cycle financial cost, initial environmental cost and life-cycle environmental cost. These different objectives can potentially lead to a different ranking of the optimal renovation strategies.

\subsection{Case study}

The selected case study is one of the three 60 years old identical residential high-rise buildings situated on the Kielpark site in Antwerp, Belgium. The building contains 96 social apartments spread over 16 floors.

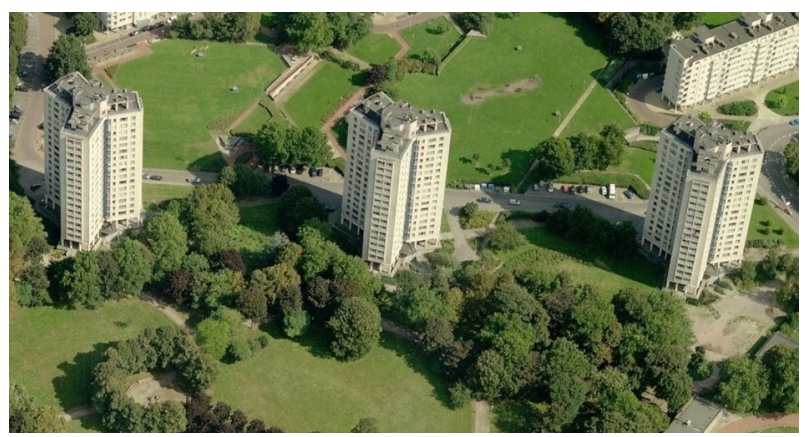

Fig. 1. The existing Kielpark high-rise buildings. 


\subsubsection{Existing façade properties}

The building façade consists of a concrete structure with uninsulated brick cavity walls in between the structure. Moreover, the façade is mainly clad with $60 \mathrm{~mm}$ thick prefabricated concrete panels. Five difference façade assemblies can be distinguished (E1E5). The individual properties together with the window (W) properties are listed in Table 3. The windows are composed of an aluminium frame without thermal break and single glazing. The roof and floor are assumed to be already insulated resulting in an U-value of $0.24 \mathrm{~W} / \mathrm{m}^{2} \mathrm{~K}$ and $0.30 \mathrm{~W} / \mathrm{m}^{2} \mathrm{~K}$, respectively. The total mean U-value of the existing building is $2.53 \mathrm{~W} / \mathrm{m}^{2} \mathrm{~K}$.

The analysis will also cover the results related to the original building before the renovation. This baseline scenario will be referred to as Scenario $0(\mathrm{~S} 0)$.

Table 2. Existing façade properties.

\begin{tabular}{c|cc} 
& $\begin{array}{c}\text { Area } \\
{\left[\mathrm{m}^{2}\right]}\end{array}$ & $\begin{array}{c}\mathbf{U} \\
{\left[\mathrm{W} / \mathrm{m}^{2} \mathrm{~K}\right]}\end{array}$ \\
\hline $\mathbf{E 1}$ & 2124 & 1.10 \\
$\mathbf{E 2}$ & 524 & 2.68 \\
$\mathbf{E 3}$ & 414 & 2.93 \\
$\mathbf{E 4}$ & 344 & 1.44 \\
$\mathbf{E 5}$ & 319 & 2.10 \\
$\mathbf{W}$ & 1920 & 5,05
\end{tabular}

As the financial system boundaries include demolition costs and some renovation strategies require the demolition of the façade components, the existing construction is also simulated in the LCC analyse. The adopted renovation scenarios (S1-S5) will consequently differ in what part of the existing façade construction is being demolished.

\subsubsection{Façade renovation scenarios}

Table 3 gives an overview of all the different scenarios considered.

Table 3. Façade renovation strategies.

\begin{tabular}{l|r} 
Façade renovation scenarios & \\
\hline Interior - aerated concrete & $\mathrm{S} 1$ \\
Interior - timbre frame wall & $\mathrm{S} 2$ \\
Exterior - open joint concrete & $\mathrm{S} 3 \mathrm{~A}$ \\
Exterior - closed joint concrete & $\mathrm{S} 3 \mathrm{~B}$ \\
Exterior - ETICS & $\mathrm{S} 4$ \\
Exterior - small glass fibre concrete & $\mathrm{S} 5 \mathrm{~A}$ \\
Exterior - large glass fibre concrete & $\mathrm{S} 5 \mathrm{~B}$
\end{tabular}

For each strategy, nine different insulation thicknesses are included in the analysis, i.e. $50 \mathrm{~mm}$, $60 \mathrm{~mm}, 80 \mathrm{~mm}, 100 \mathrm{~mm}, 120 \mathrm{~mm}, 140 \mathrm{~mm}, 160 \mathrm{~mm}$, $180 \mathrm{~mm}$ and $200 \mathrm{~mm}$.

The baseline scenario ( $\mathrm{S} 0$ ) is a rather unrealistic scenario considering the age and the state of the building. If the building is not renovated, the maintenance will rise because of the more frequent repair works. Therefore, several conservation scenarios
(C) are included to allow a more realistic comparison with the façade renovation scenarios. Per renovation scenario, an insulation thickness of $0 \mathrm{~mm}$ is added. In this way, conservation costs are estimated on the basis of a cladding renewal and maintenance according to the related renovation scenario (i.e. $\mathrm{C} 1, \mathrm{C} 2, \mathrm{C} 3 \mathrm{~A}, \mathrm{C} 3 \mathrm{~B}, \mathrm{C} 4$, C5A, C4B). This does not apply to the interior wall insulation systems. Here, only an additional maintenance cost related to the existing interior plaster is included.

Subsequently, four different window solutions are defined: retaining the existing window (W0), replacing the single glazing by $\mathrm{HR}++$ glazing $\left(\mathrm{U}=1.10 \mathrm{~W} / \mathrm{m}^{2} \mathrm{~K}\right)$ (W1), replacing the glazing and frame with $\mathrm{HR}++$ glazing $\left(\mathrm{U}=1.10 \mathrm{~W} / \mathrm{m}^{2} \mathrm{~K}\right)$ and an aluminium window frame $\left(\mathrm{U}=2.10 \mathrm{~W} / \mathrm{m}^{2} \mathrm{~K}\right)(\mathrm{W} 2)$ or a $\mathrm{PVC}$ window frame $\left(\mathrm{U}=1.90 \mathrm{~W} / \mathrm{m}^{2} \mathrm{~K}\right)(\mathrm{W} 3)$.

The combination of all above mentioned measures described above results in 280 different combinations (10 insulation thicknesses, 7 wall systems, 4 window scenarios).

\section{Results}

This paper examines the impact of life-cycle assessment on the initial Pareto optimal renovation set outcome typically only based on the financial construction costs and the energy performance. This part therefore highlights the importance of a multi-faceted decision-making basis. In particular, noticeable differences in trends are investigated, while less attention is paid to the individual results. Moreover, the results are solely based on one specific case. This paper therefore does not intend to provide general guidelines about the best solution to be used in renovation projects.

The graphs shown in this section report all 280 scenarios and the base-line scenario in one scatter plot. This results in different point clouds with a specific colour (please refer to table 3 for the colour assigned to each scenario). Each strategy consists of four linearly curved point clouds associated with the four different window solutions, in which each individual point represents a different insulation thickness. The optimal scenarios are encircled in black. This approach allows to easily interpret the figures and to quickly identify specific trends related to each studied scenario.

In the section 3.1, the importance of a life-cycle approach is first analysed comparing the initial financial costs with the life-cycle financial costs (Fig. 2) and the initial environmental costs with the life-cycle environmental costs (Fig. 3). Further-more, the impact of a multi-objective approach is examined in the section 3.2 by expressing the financial life-cycle results, the environmental life-cycle results as a function of the energy performance (Fig. 4-6). In order to show all criteria in one blanket graph, the financial and environmental life-cycle costs are enumerated and depicted as a function of the operational energy use (Fig. 7). 


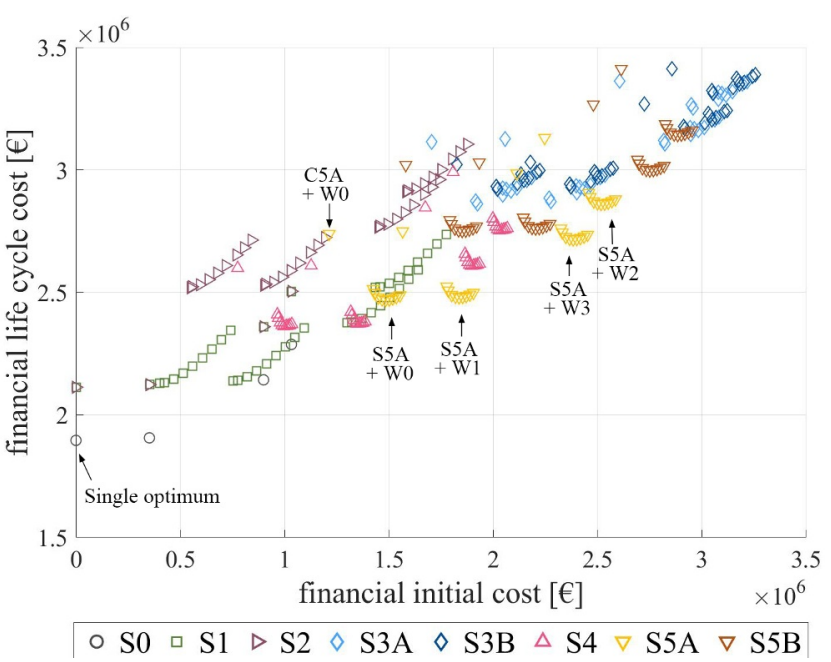

Fig. 2. Financial: initial versus life-cycle cost.

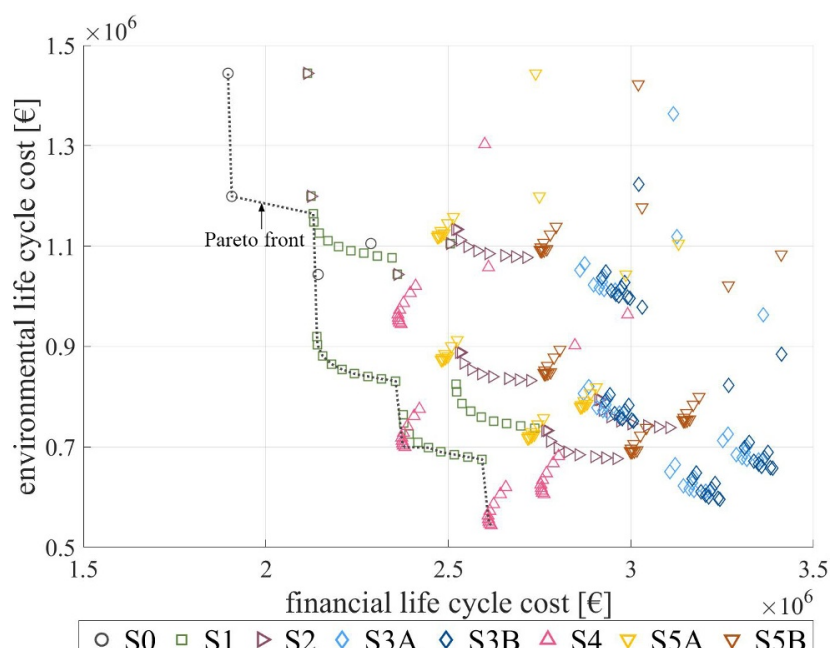

Fig. 4. Financial versus environmental life-cycle cost.

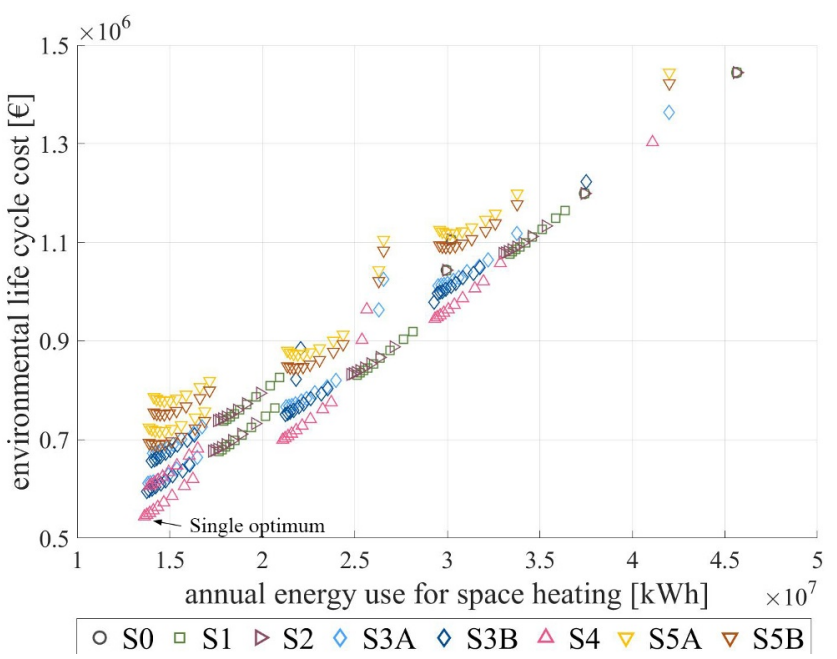

Fig. 6. Environmental life cycle cost versus operational energy use

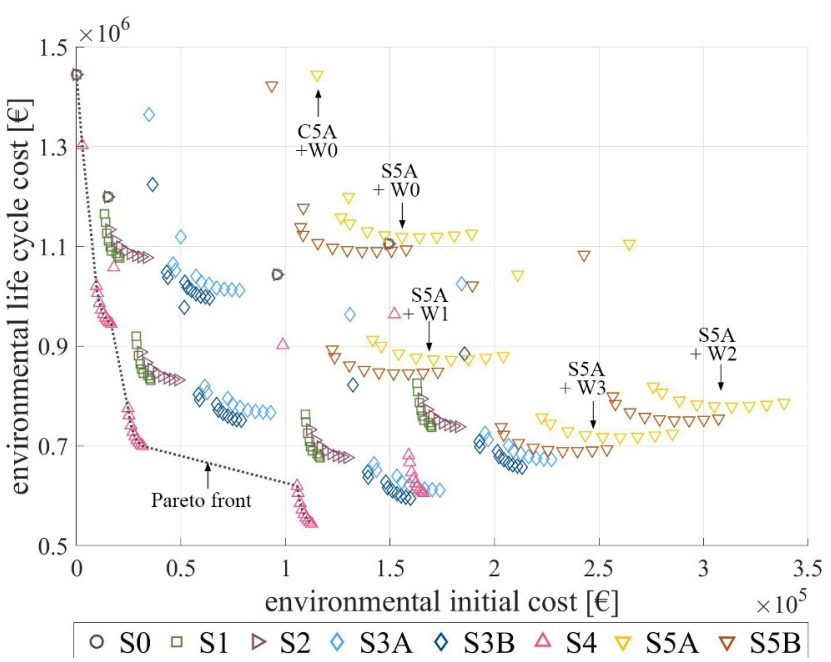

Fig. 3. Environmental: initial versus life-cycle cost.

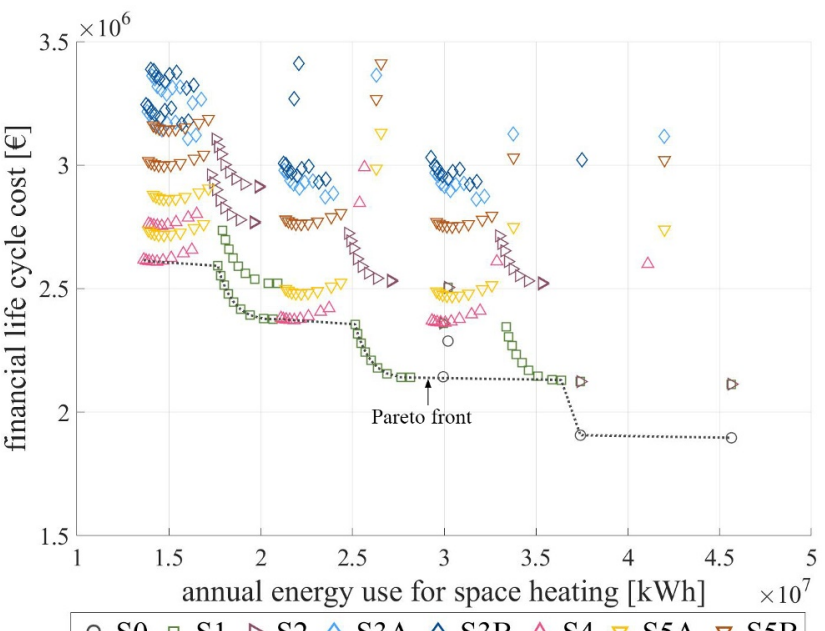

$\circ \mathrm{S} 0 \square \mathrm{S} 1 \triangleright \mathrm{S} 2 \diamond \mathrm{S} 3 \mathrm{~A} \diamond \mathrm{S} 3 \mathrm{~B} \Delta \mathrm{S} 4 \nabla \mathrm{S} 5 \mathrm{~A} \nabla \mathrm{S} 5 \mathrm{~B}$

Fig. 5. Financial life cycle cost versus operational energy use

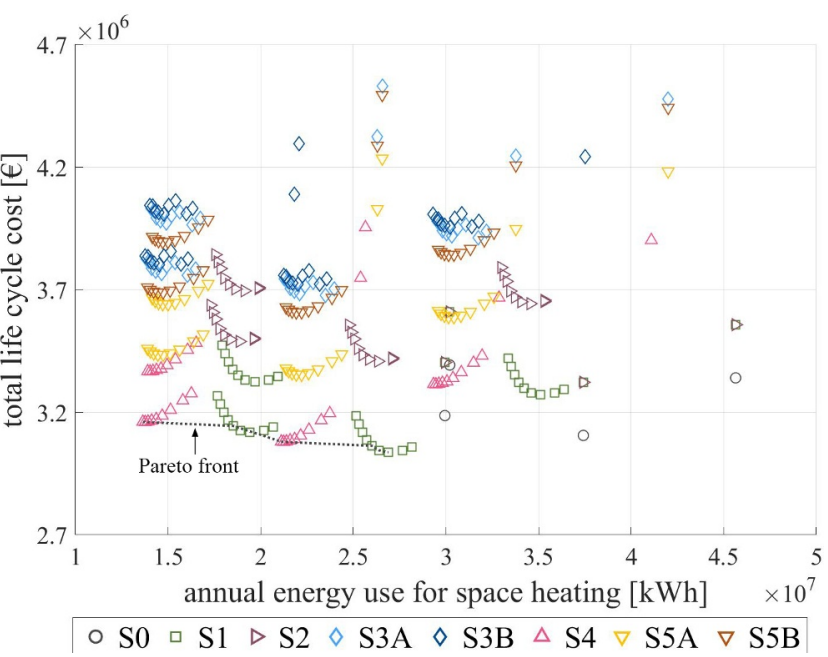

Fig. 7. Total life cycle cost versus operational energy use 


\subsection{A life-cycle approach for decision-making}

\subsubsection{Initial versus life-cycle financial cost}

Figure 2 compares the financial initial cost with the financial life-cycle cost. Considering all renovation scenarios, only one Pareto optimum is noticed, i.e. the non-renovated situation. In other words, no alternative strategy has either a lower initial cost nor a lower lifecycle cost. This is mainly due to the ratio of the different contributing costs. The relatively large share of the initial costs - up to $63 \%$ of the total lifecycle cost - as opposed to the supplementary limited share of energy cost, causes the various renovation measures not paying off compared to the non-renovated situation.

Furthermore, analysing the seven different renovation strategies (colours) separately, the initial cost is in most cases not compensated by the resulting energy savings. This is particularly evident on the basis of the upward trend of the interior insulation strategies S1 and S2. A higher initial cost always results in a higher lifecycle cost.

On the other hand, the results of scenarios S3A, S3B, S4, S5A and S5B show that it is only profitable to invest in renovation measures up to a certain insulation thickness. This is visible in Figure 2 based on the initial decreasing trend, which then increases again from the lowest life-cycle financial cost, i.e. the optimal insulation thickness. The downward trend shows that for a small additional investment, a considerable reduction of the life cycle cost is obtained.

Figure 2 also shows that none of the scenarios in which windows are replaced are part of the pareto front. Hence, investing in more performant windows is not a cost-optimal choice.

\subsubsection{Initial versus life-cycle environmental cost}

Figure 3 in turn depicts the initial environmental cost as a function of the life-cycle environmental cost. The original non-renovated solution is only a pareto optimum due to its zero initial cost, whereas the life cycle cost is significantly higher than the various alternative pareto optimal scenarios. Note that, when assuming that only the cladding is renewed (cf. insulation thickness zero), not renovating the building is no longer an optimal option. The figure clearly shows that environmental considerations lead to solutions with a higher energy performance. This is strongly related to the proportional contribution of the different phases to the life-cycle costs. In contrast to the financial results, the operational energy savings (and thus environmental benefits) due to a larger insulation thickness outweighs the initial environmental cost.

Analysing the considered renovation scenarios separately, all curved point clouds show a declining trend up to a certain minimum. This is again linked to reaching the optimal insulation thickness. In this study, this optimal insulation thickness is only reached for strategy S5A and S5B due to the higher contribution of the initial costs compared to the life-cycle costs. For the remaining strategies it is clear that the environmental optimum relates to an insulation thickness above $200 \mathrm{~mm}$.

Furthermore, the steep downward trend of S1 and S4 contrasts with the slow decline and spread initial costs of $\mathrm{S} 5 \mathrm{~A}$ and S5B. Respectively, this indicates that only a limited additional environmental cost is required for $\mathrm{S} 1$ and S4 to achieve significant operational energy savings and that, on the other hand, for S5A and S5B large additional initial environmental costs yield small longterm savings.

Furthermore, investing in new glazing and/or new PVC windows is profitable from an environmental point of view as only the scenarios with new aluminium windows are never part of the Pareto front.

\subsection{A multidimensional approach for decision- making}

\subsubsection{Life-cycle financial versus environmental cost}

Comparing Figure 2 and 3 already gives a first impression of the importance of a multidimensional decision-making process. Pareto-optimal results related to financial and environmental costs clearly do not coincide given the observed opposite trends. Although it is rarely profitable to invest in renovation measures from a financial point of view, not renovating is a sustainable option from an environmental point of view.

The discrepancies between, and relative weight of the financial life-cycle costs and the environmental lifecycle costs are shown in Figure 4. Considering all renovation scenarios, 28 Pareto solutions are found. The solutions contain scenario S0 with and without replacement of the glazing, various scenarios of S1 (50mm-60mm-W0, 50-200mm-W1， 120-200mm-W3) and of S4 (120mm-200mm-W2, 120mm-200mm-W3).

The renovation strategies evaluated separately, show remarkably different trends which correspond to the opposite trends mentioned before. The results regarding internal insulation strategies $\mathrm{S} 1$ and $\mathrm{S} 2$ show a similar decreasing trend with a large spread in financial lifecycle costs meaning that a large increase of the financial life-cycle costs leads to an small decrease of the environmental life-cycle cost resulting in several optimal solutions. On the other hand, the point cloud shape of S4, S5A and S5B is vertically curved. The kink in the curve represents the scenario with the lowest financial life-cycle cost. From that point on a rather limited financial increase leads to lower environmental life cycle costs causing larger insulation thicknesses to be more optimal.

\subsubsection{Life-cycle financial cost versus operational energy use}

In a best case scenario decisions are currently based on a trade-off between the operational energy use for space heating and the financial life-cycle cost. Figure 5 depicts 
this relation. The same 28 Pareto optima are found as in Figure 4. This does not mean that environmental considerations are negligible, but this is largely due to the small proportional contribution of the initial material impact on the total environmental cost.

While strategies S1 and S2 show a significant spread of the financial life-cycle cost for a given decrease in operational energy use, there is only a limited difference between the financial life-cycle costs regarding the other three strategies for the same decrease in operational energy use.

\subsubsection{Life-cycle environmental cost versus operational energy use}

As shown in Figure 6, an analogous comparison is made between lifecycle environmental costs and operational energy use. Whereas 28 scenarios seem to be optimal from just a financial point of view, there is only one option Pareto optimal based on environmental considerations, namely scenario S4 with the largest insulation thickness $(200 \mathrm{~mm})$. This option appears to be also optimal from a financial perspective.

Furthermore, a uniform linear trend can be identified for all considered strategies. For a specific decrease in operational energy use, the environmental life-cycle cost decreases. The straight upward point clouds again emphasise the substantial contribution of the operational energy use in the LCA analysis compared to declining and horizontal point clouds of the LCC analysis.

\subsubsection{Total life-cycle cost versus operational energy use}

Finally, to get an idea of the Pareto optimal solutions taking into account both financial and environmental, the environmental life-cycle cost is enumerated to the financial life-cycle cost and then plotted in relation to the operational energy use for space heating.

The combined Pareto front, illustrated in Figure 7, strongly correlates with the financial figure based on the observed point cloud shapes. Although, the financial aspect seems to dominate, adding the environmental cost to the financial cost eliminates some financial-optimal results excluding 20 options of the 28 financial optima. This leaves 8 scenarios optimal.

Moreover, a shift of the Pareto front is noticed leading to optimal solutions that have a larger insulation thickness. Note that, the original non-insulated situation is no longer part of the Pareto front.

\section{Conclusions}

The aim of this paper was to quantify the effect of integrating life-cycle and multidimensional thinking in the decision-making process considering different renovation strategies, in contrast to the standard approach which is only based on the financial construction costs and the operational energy use for space heating.
By depicting the initial costs in relation to the lifecycle cost, life-cycle thinking seems relevant in the decision-making process both from a financial and an environmental point of view. Whereas the conventional mind-set is to keep the construction costs to a minimum, annual operational energy savings could potentially compensate the initial costs. This statement is verified from an environmental perspective as the extra initial cost to increase the insulation level is most often compensated by the associated energy savings. According to the financial results this applies only to a limited number of scenarios.

Moreover, the results show that the financial and the environmental Pareto optimal solutions do not coincide. This is mainly due to the different contribution of each life cycle phase regarding LCC and LCA. Considering a lifespan of 30 years, the obtained operational energy savings do not compensate the initial financial cost leading to only one optimum, the non-renovated situation. This is in contrast to the substantial contribution of the operational energy use to the environmental life-cycle costs resulting in multiple optima with a larger insulation thicknesses. However, this proportional contribution is strongly dependent on the assumed lifespan. While the operational phase will gain importance considering a longer lifespan, the influence of the operational energy costs will be limited for shorter lifespans.

The combined Pareto front of both aspects correlates strongly with the financial figure. Although the financial aspects seem to dominate, adding the environmental cost to the financial cost eliminates financial-optimum options. causes a shift of the Pareto front to more performant scenarios.

Considering a life-cycle approach and multiple dimensions in the decision-making process clearly influences the cost-based results and provides a more substantiated evaluation of different renovation strategies.

\section{References}

1. I. Artola, K. Rademaekers, R. Williams, and J. Yearwood,. Boosting building renovation: What potential and value for Europe? European Union (2016)

2. European Commission. Going climate-neutral by 2050: A strategic long-term vision for a prosperous, modern, competitive and climate-neutral EU economy. European commission: EU publications (2019)

3. BPIE. Future-proof buildings for all Europeans. BPIE Buildings Performance Institute Europe, Belgium (2019)

4. Eurima. Renovation tracks for Europe up to 2050. Ecofys, Germany (2012)

5. K. Mjörnell, A. Boss, M. Lindahl, S. Molnar, Sustainability, 6, 4227-4245 (2014)

6. L. Malmgren, K. Mjörnell, Sustainability, 7, 1252112538 (2015) 
7. D. Heidenthaler, M. Gnigler, M. Leeb, M. Embacher, and P. Schweizer, P. IOP Conference Series: Earth and Environmental Science, 323:012003 (2019)

8. W. Debacker, K. Allacker, L. Delem, A. Janssen, F. De Troyer, C. Spirinckx, T. Geerken, and J. Van Dessel, Delft University of Technology : ERSCP and EMSU conference proceeding (2010)

9. G. Verbeeck, K.U. Leuven: PhD thesis (2007)

10. J. Van der Veken, J. Creylman, and T. Lenaerts, Kenniscentrum Energie, Geel, Belgium (2013)

11. Aspen. Aspen index pro - nieuwbouw. Aspen, East Flanders, Belgium (2014)

12. ABEX (2019). Historisch overzicht van de index: de $A B E X$ index sinds 1914. Retrieved from https://www.abex.be/nl/indexen-tijdschriften/indexabex/historisch-overzicht-van-de-index/

13. Eurostat. Gas prices for household consumers - biannual data (from 2007 onwards). Eurostat (2019).

14. Aspen. Aspen index pro - renovatie. Aspen, East Flanders, Belgium (2003).

15. K. Allacker, K.U.Leuven: PhD thesis 2010

16. Federal planbureau. Economische vooruitzichten 2019-2024 - versie van februari 2019. Federaal Planbureau, Brussels, Belgium (2019)

17. Federal planbureau. Het Belgische energielandschap tegen 2050 - Een projectie bij ongewijzigd beleid. Federaal Planbureau, Brussels, Belgium (2017) (in Dutch)

18. Ecoinvent Centre (2018). Ecoinvent 3.5. Available at: https://www.ecoinvent.org/database/olderversions/ecoinvent-35/ecoinvent-35.html

19. OVAM. Milieugerelateerde materiaal-prestatie van gebouwelementen. OVAM, Mechelen, Belgium (2012)

20. M.A.J. Huijbregts, et al., ReCiPe 2016: A harmonized life cycle impact assessment method at midpoint and endpoint level - Report I: Characterization. RIVM Report 2016-0104 (2016)

21. C. Sáez, and J. Requena, Ecological Economics, 712-725 (2007)

22. K. Calle, De ontwikkeling van (kosten)optimale gevelrenovatiestrategieën voor resientiële hoogbouw. Ghent University: Master thesis (2015) 